\title{
Harmonizing Teaching Tools with Cognitive Learning Outcomes in the Teaching of Economics
}

\author{
Mohsen Edalati ${ }^{1}$ \\ ${ }^{1}$ Department of Economics, Azad University of Iran, Marvdasht Branch, Fars Province, Marvdasht, Iran \\ Correspondence: Mohsen Edalati, Department of Economics, Azad University of Iran, Marvdasht Branch, Fars \\ Province, Marvdasht, Iran. E-mail: Edalatimohsenbz@gmail.com
}

Received: November 12, 2016

Accepted: December 15, 2016 Online Published: December 18, 2016

doi:10.5539/ijef.v9n1p119

URL: http://dx.doi.org/10.5539/ijef.v9n1p119

\begin{abstract}
The selection of teaching tools is a key determinant of the extent to which the anticipated learning outcomes of a course will be realized. As such, choosing optimal teaching tools can be a greatly effective course of action to enhance learning in the classroom. As Terregrossa et al. (2009) point out, "it is ironic that the practitioners of the discipline devoted to the study of efficiency principles [i.e. economics] are implicitly accused of being inefficient in their approach to teaching that discipline." The purpose of the present paper is to first explain cognitive learning outcomes as well as review both traditional and modern teaching tools in the context of economics. Next, the appropriate teaching tools that match correspondingly with each specific cognitive learning outcome are proposed in the setting of teaching economics. To this end, the paper concentrates on Benjamin Bloom's (1956) taxonomy of cognitive domains to describe different cognitive learning levels. Then, a diverse set of teaching tools suitable to teach economics are corresponded to different cognitive learning outcomes. More specifically, the present paper aims to introduce different teaching tools - including course formats, major teaching methods, and teaching moves - corresponding to different levels of cognitive domain in the context of teaching economics. Finally, it is argued that economics instructors should select teaching tools as well as contents, readings, in-class activities, assignments, and assessment formats after formulating the learning outcomes of the course, so that the teaching tools selected can facilitate students' learning and help them achieve the anticipated learning outcomes more readily.
\end{abstract}

Keywords: teaching of economics, pedagogy, teaching tools, cognitive learning outcomes

\section{JEL Classification: A20}

\section{Introduction}

The selection of teaching tools is a crucial determinant of the degree to which the anticipated cognitive learning outcomes of an academic course are realized. As such, choosing the optimal teaching tools can be an effective task to enhance learning. As Terregrossa et al. (2009) point out, "it is ironic that the practitioners of the discipline devoted to the study of efficiency principles [i.e. economics] are implicitly accused of being inefficient in their approach to teaching that discipline." This is indeed a legitimate concern that motivates the issue being discussed in the present paper. One way of setting up such an optimization problem could be as below:

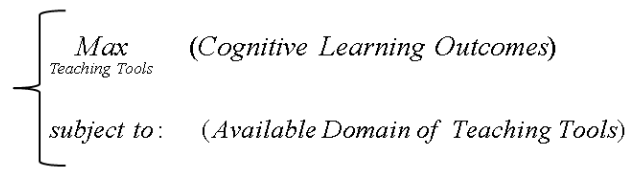

As a result, the optimum teaching tools are the ones that maximize the achieved level of the pre-specified learning outcomes of the course. The natural, generic solution to this optimization problem could be written down in mathematical notations as the following:

Optimal Teaching Tools $=\underset{\text { Teaching Tools }}{\text { Arg } \max }($ Cognitive Learning Outcomes $)$

Although finding such an optimal point could potentially be highly costly and time-consuming, if not practically unfeasible, for economics instructors, there are still compelling pieces of evidence in the literature of education 
as well as some common understanding and consensuses among economics educators working on different areas in economics, following which can ensure economics instructors that they are indeed converging to the mentioned optimal point, i.e. the utilization of optimal teaching tools that maximizes the level of learning outcomes. In sum, the optimal teaching methods are the ones that help instructors attain the highest possible level of cognitive learning outcomes. Moreover, there are some economic concepts and courses that are naturally tailored to be taught solely by some specific teaching tools. Throughout the paper, a few of these methods and their relevance to economics courses are discussed to some extent.

The research questions that the paper is to answer are: What are the optimal teaching tools for teaching economics courses having different cognitive learning outcomes? What are some notable traditional, conventional, and modern examples of these teaching tools which have been proposed in the economics education literature and have been applied in economics classrooms?

The present paper is to first explain cognitive learning outcomes as well as review both traditional and modern teaching tools in general and also in some extent in the specific context of economics. Next, the appropriate teaching tools that match correspondingly with each specific cognitive learning outcome are proposed in the setting of teaching economics. To do so, the paper concentrates on Benjamin Bloom's (1956) taxonomy of cognitive domain to describe different cognitive learning levels. Afterwards, a diverse set of teaching tools suitable to teach economics are corresponded to different cognitive learning outcomes. Finally, it is argued that economics instructors should select teaching tools as well as contents, readings, in-class activities, assignments, and assessment formats after formulating the learning outcomes of the course, so that the teaching tools selected can facilitate students' learning and help them achieve the anticipated learning outcomes more readily.

The remaining sections of the paper are organized as follows: Section 2 reviews the related literature in short. Section 3 defines learning outcomes in a general sense and broadly. Section 4 focuses exclusively on 'cognitive' learning outcomes, and explains them through Bloom's (1956) taxonomy of cognitive domain in some detail. Section 5 elaborates on different types of teaching tools, i.e. course format, major teaching methods, and teaching moves. Section 6 provides a toolkit for selecting preferred teaching tools corresponding to learning outcomes. Eventually, a conclusion on the discussion will be drawn in section 7.

\section{Literature Review}

Nilson (2010) provides a great discussion on the selection of teaching tools. As she reports, Derek Bok (2006) argues that the selection of teaching tools is even more important than the content an instructor selects, and he complains that faculty discussions ignore the topic of pedagogy. He then goes on to say that research findings concerning the relationship between teaching tools with learning and retention is very discouraging, suggesting that the average student cannot recall most of the factual content of a lecture within fifteen minutes after the lecture finishes. Nonetheless, as he notes, "lessons learned through more active teaching methods can leave students changed forever."

Becker and Watts (1995) examine teaching tools and methods in undergraduate economics, concluding that although lectures have long been the dominant teaching method in undergraduate economics courses, they are not the only method anymore. They bemoan the fact that "much of the recent soul-searching in the discipline has largely ignored the issue of promoting the use of innovative and more active forms of teaching and learning." They review the literature on new teaching tools and methods, and argue that "this should also be a part of the current debate about curriculum and training reforms for the profession."

Fish and McKeen (1985) investigate different learning needs in economics education at the community college level using the Myers Briggs Type Indicator as a surrogate measure for learning style. They studied 275 beginning economics students at the Alexandria Campus of the Northern Virginia Community College. Their results suggest that the learning needs of most of students who did not do well in economics were decidely different than those of most of students who did well in economics. Their other findings imply that most students who enrolled in the introductory economics classes had a learning preference other than dominant instructional formats found in typical economics classrooms. They finally suggest that if more students are to succeed in these courses, alternate instructional formats and teaching tools must be developed and delivered.

Tulbure (2012) compares two groups of pre-service teachers (with Educational Sciences and Economic Sciences major) in order to find: (1) their learning-style preferences, (2) the most effective teaching strategies and instructional tools for each learning style, and (3) any possible differences between their academic achievements and outcomes. In this study, a between-subject design was utilized to analyze the data which had been collected through a survey method. She assumed that when comparing the students in Educational Sciences with the students attending Economics, certain teaching methods and strategies will lead to different academic outcomes 
for students having a similar learning preference. She observed significant differences between the two groups of students that had emerged in relation with the most effective teaching strategies corresponding to each learning style category. She also found that both categories academically performed better when they were taught using a teaching method that involved the graphical organization of information.

Moosavian (2016) examines the importance of visualization in the teaching of economics, and complains that many of the research studies in the area of economics education have suggested 'general' solutions to the issues with the teaching of economics, and not 'specific' practical solutions. He then provides a practical solution to one of the identified problems with the teaching of economics; that is, lack of a clear way to teach a structured body of knowledge rather than scattered pieces of information. As he suggests, in many cases an effective way to teach such a structure is providing the visual "big picture" of the subject matter being covered. He has also provided notable examples, specific to the teaching of economics, of how to put the idea of providing visual "big pictures" into practice for the courses intermediate macroeconomics, advanced microeconomics - case of consumer theory and case of production theory (Moosavian (2016b, c, d); Naumenko and Moosavian (2016)). Principally, this is a suggested teaching tool proposed by him to teach a structured body of economic knowledge that enhance learning in the classroom in terms of comprehension, retention, clarity, big-picture thinking, as well as critical thinking.

Zhang (2016) proposes different teaching tools and modes in the teaching of economics which are suitable for accommodating different learning styles classified by Fleming and Mills's sensory-based learning style typology. According to him, "Students prefer to learn in different ways," and this variety suggests that instructors should teach their course materials in different ways so as to cater to different learning styles. He also provides some prominent examples of each teaching tool introduced in the literature of economic education. Finally, he argues and suggests that it is more reasonable to take a multimodal approach to the teaching of economics, given the recent advancements and availability of various technologies, existing evidence of the higher effectiveness of multimodal teaching, general growing consensus on the issue, etc. Zhang (2016) also points out to the fact that though "all economics instructors undergo strict training in economic theory; however, they rarely and barely receive training in the principles of education." As a result, many economics instructors may not be taking advantage of all of existing teaching resources efficiently, and consequently, may not be providing students with an optimal education (Terregrossa et al., 2009; Bartlett \& King, 1990).

Frank (2007) stresses the vitality of the manner through which economic content is taught. According to him, the form in which ideas are conveyed is as important as the content itself. As Reich (2000) puts it, "We're creating a one-size-fits-all system that needlessly brands many young people as failures, when they might thrive if offered a different education." Reich's statement somehow implies that different teaching tools should be used by instructors when targeting different learning outcomes, so that students could more easily prosper academically professionally in the discipline.

After having this brief literature review, it can readily be seen that although there are studies that have tried to address the idea of matching teaching tools with students' learning styles or with other factors, less, if not no, attention has been paid to matching teaching tools to the cognitive learning outcomes in the context of teaching economics, and this is the existing gap in the literature that the present paper is to fill in.

\section{Learning Outcomes}

As Cross (1988) once put it, "Teaching has only one purpose, and that is to facilitate learning." As a result, in some sense, teaching and learning can be thought of as two sides of the same coin. This is one reason why the course design process must be based on the desired learning outcomes of the course, i.e. what the instructor of the course wants her students to be able to do by the end of the course. When a course is designed on the basis of its learning outcome, then it is guaranteed that a higher level of learning outcomes will be achieved, since the process steers instructors as well as students toward attaining the learning outcomes of the course.

By definition, "a learning outcome is a statement of exactly what students attending a course should be able to do after completing the course or at specified points during the course" (Nilson, 2010). Learning outcomes are written from a student's perspective. They are definitely promises, and this is the mission of instructors to make these promises come true. The ultimate goal of teaching is to help students achieve learning outcomes of the course. Hence, it makes the most sense to design the course delivery according to the course learning objectives and outcomes from the first place.

Learning outcomes are of five types (Note 1): psychomotor, affective, social, ethical, and cognitive (Note 2). Among these, teaching economics has more to do with the last two ones. In other words, normative economics has mainly to do with ethical learning outcomes, while positive economics has mostly to do with cognitive 
learning outcomes. Among these two, this paper focuses on the latter since teaching positive economics is the main component of economics curriculum in universities nowadays.

\section{Cognitive Learning Outcomes and Course Design}

Practically, every college course has cognitive learning outcomes. Cognitive learning outcomes are those that are related to thinking in some way. The words cognition and cognitive refer to the process of understanding and thinking about facts, terms, concepts, ideas, relationships, patterns, and conclusions. Examples include: knowledge and remembering; comprehension and translation; application; analysis; synthesis and creation; and evaluation (Nilson, 2010).

Bloom (1956) has proposed a very useful, handy, and popular taxonomy for constructing cognitive outcomes. The framework that he introduces presumes a sequence of six levels of cognitive domain, starting from the most basic, representing the lowest-level process of remembering stored knowledge, continuing with multiple intermediate cognitive levels, and ending with the most abstract, the highest level of general evaluation. These cognitive levels are defined, by Nilson (2010), as follows:

- Knowledge: The ability to recall and re-produce previously stored and learned material;

- Comprehension: The ability to apprehend the meaning of material and re-state it in one's own words;

- Application: The ability to use and apply learned material in new and concrete situations;

- Analysis: The ability to break down material into its components in order to better understand its underlying, organizational structure;

- Synthesis: The ability to put together pieces of material so as to to form a new whole;

- Evaluation: The ability to evaluate and judge the value of material for a given purpose.

The first two cognitive levels indeed furnish foundations, and as a result, should not be considered as the endpoint of education. After building up such a concrete foundation, instructors can foster critical-thinking and problem-solving skills. Then, instructors can expect students to get engaged in challenging underlying assumptions of models, structure of methods, and the like. As such, in economics education, the lower levels of the cognitive domain have more to do with the anticipated cognitive learning outcomes of undergraduate economics studies, whilst the higher levels of it have more to do with the anticipated cognitive learning outcomes of graduate economics studies, during which students are mostly expected to be able to contribute to a cause, and create something new (Note 3).

As mentioned above, in order to be able to perform one level of thinking, one first needs to have achieved the corresponding lower-ranked cognitive outcomes, and also be able to perform all the lower-order thinking operations. In the same manner, a well-designed course should account for the sequence of the learning outcomes to lead students up to the higher levels of the cognitive domain. It is way too obvious that a student has to be able to define the basics of certain concepts, and understand the related principles, and remember the related facts before thinking about those in a more complex framework. As Nilson (2010) explains, a typical course design is a skeleton, with which the instructor has to start developing the course into a more detailed plan- "that is, filling it out by putting muscle and connective tissue on the bone structure." To sum up, wise instructors should select contents, teaching tools, readings, in-class activities, assignments, and assessments after formulating the learning outcomes, so that they can aid students in achieving the formulated learning outcomes.

\section{Teaching Tools: Course Formats, Teaching Methods, and Teaching Moves}

Teaching tools can be broadly classified under three categories: course formats, major teaching methods, and teaching moves. These three are briefly explained below.

\subsection{Course Format}

A course format defines the course meetings, the setting, and the expected activities for the class period, examples of which include lecture, discussion sections, seminars, lab sessions, skill activity sessions, or any combinations of these. Though instructors might probably think of formats as unchangeable and given for the course they teach, they still can make a case to their department chair in case they believe that a different format to their course would enhance their students' learning, and help them achieve the course leaning outcomes more effectively. According to Nilson (2010), although the direct learning impact of different course formats are not exactly known, we still do know quite a bit about the effects of closely related variables, such as the degree of in-class student activity and class size (for example, you can see Hoyt and Perera (2000), but since course formats are not the focus of the present paper, it is not discussed in great detail here). 
According to Zhang (2016), "economics courses are taught mostly using traditional formats such as lectures along with the presentation of visual instruments such as graphs and charts, which is widely known as the "chalk and talk" method," and most of the time, the existence of different cognitive learning outcomes are ignored. This way, the potential improvement in student performance which is achievable from matching instructors' teaching methods with cognitive learning outcomes is lost. Moreover, there are some economic concepts and courses that are especially difficult to teach solely by conventional and traditional teaching instruments such as lecture and discussion. For instance, econometrics courses and research methods are two examples that need others course formats than pure lecture. If we accept the fact that that different economics courses have different desired cognitive learning outcomes, and that research suggests that students' performance level can depend inversely on the gap between instructors' chosen teaching tools and the optimal teaching tools, and that traditional formats of teaching economics do not appeal to all students, then a reasonable approach to teaching economics would be accommodating various teaching formats in teaching different courses. For the mentioned reasons, economics instructors should sometimes consider other course formats than only pure lectures so as to effectively achieve the learning outcomes of economics courses.

\subsection{Major Teaching Methods}

The word major here refers to the fact that these teaching methods require considerable time to be completed, e.g. the whole semester duration, or at least multiple weeks of it. In general, there is a wide variety of teaching methods. These include lecture, recitation, directed discussion, writing and speaking exercises, classroom assessment techniques, group work/learning, student-peer feedback, just-in-time teaching, case method, multi-week assignments or in-class activities that require considerable time, small-group activity during a term-long course, interactive lectures, service-learning project, inquiry-based or inquiry-guided learning, problem-based learning, project-based learning, role plays, simulations, case methods, experiential methods, software programs, experiments in the classroom (e.g. see Holt (1999) and Holt and Laury (1997) for examples in the setting of economics courses), service learning with reflection, fieldwork and clinicals (Nilson, 2010). Appendix 1 reviews the basic definitions of these major teaching methods. In section 6, these teaching methods are visually linked to their corresponding cognitive learning outcomes.

\subsection{Teaching Moves}

The term 'teaching moves' refers to the ways through which an instructor can further explain and elaborate on material. Teaching moves should be viewed as mini methods compared to major teaching methods. In comparison, they usually require much less time and commitment. Examples of purposes that an instructor can pursue using teaching moves are to help students recall the readings and to explain a complex point or new material. Instances of teaching moves include the learning strategies and tips that the instructor shares with his class (i.e. teaching how to learn), the short in-class activities and exercises that the instructor asks students to do, or the type of the questions the instructor ask them to contemplate. One advantage of these teaching tools is that if one specific type of them does not seem to function well, then the instructor can readily try another one. In this sense, teaching moves are the most flexible set of teaching tools, since they can be changed even during the course according to the feedback the instructor receives from the students, as opposed to course formats that are hardest teaching tool to be changed once the course has started. Figure 1 compares the three mentioned teaching tools in terms of the time needed to implement the tool and the flexibility that each tool provides to change it if needed.

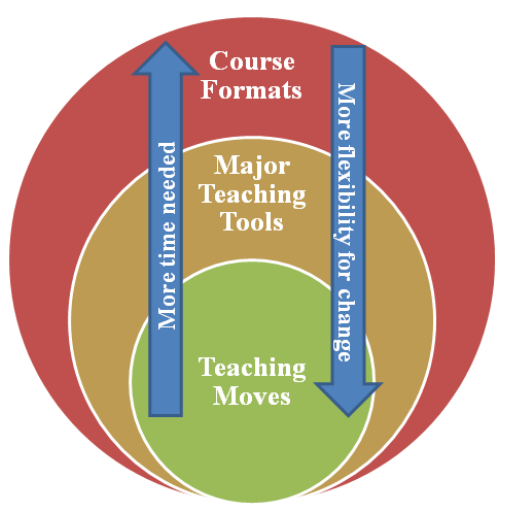

Figure 1. Comparison of the three teaching tools in terms of the time needed to implement the tool and the flexibility that each tool provides for its change if needed 
An additional advantage of teaching moves is the quick feedback that the instructor can get on his students' possible misapprehension and mistaken learning. In this sense, many of teaching moves can serve as both assessment tools and teaching tools. Nilson (2010) presents a rich set of tables that help instructors to devise additional teaching moves to help them achieve their instructional purposes. In what follows, a set of teaching moves are mentioned, which are have been suggested by Goodson (2005). In addition to pointing out to general teaching moves, a few economics-specific examples of teaching moves introduced in the recent economics education literature are also mentioned.

Different teaching moves can serve and enhance different levels of cognitive domains. Examples of the teaching moves that can enhance knowledge are as follows: suggesting prior and prerequisite knowledge to which students can connect new and future information and knowledge (an economics-specific example is interactive graphic syllabus introduced by Moosavian (2017) for the intermediate macroeconomics course); classifying knowledge into coherent groups, classifications, categories, or themes; sharing ways, methods, and devices to improve memory such as mnemonic patterns, maps, charts, comparisons, and groupings; and highlighting of key words or first letters, visual images, and rhymes.

Examples of the teaching moves that can enhance comprehension are as follows: outlining new or upcoming material in simple form (general instances are the graphic syllabus introduced by Nilson (2009), the interactive syllabus introduced by Richards (2003), and the interactive graphic syllabus introduced by Moosavian (2017), and economics-specific examples are Moosavian (2016c) and Naumenko and Moosavian (2016) and Moosavian (2016b) that provides the visual big pictures of advanced consumer theory, advanced producer theory, and intermediate macroeconomics, respectively); concept-mapping or mind-mapping new or upcoming material (a general instance is the outcome map introduced by Nilson (2009) and an economics-specific example is the notion of visual "big pictures" put forth by Moosavian (2016)); explaining with concrete examples, or metaphors; summarizing information or knowledge (an economics-specific example is Zeytoon Nejad (2017) which compares the classical school of economic thought with the Keynesian school of economic thought in terms of 50 aspects in a summary table); and finally, constructing visual representations of main ideas (mind or concept maps, tables, flowcharts, graphs, diagrams, or pictures).

Examples of the teaching moves that can enhance application are as follows: giving multiple examples of a phenomenon that are meaningful to students; defining the procedures for use, including the rules, principles, and steps; explaining steps as they are applied like an algorithm; defining appropriate procedures for different contexts, problems, situations, or goals; explaining the reasons why procedures work for different types of situations or goals; research replications using the same datasets; and finally making a smooth transition from simple, highly structured problems to more complex, less-structured ones.

Examples of the teaching moves that can enhance analysis are as follows: pointing out the important and the unimportant features or ideas; pointing out examples and non-examples of a concept; highlighting similarities and differences; emphasizing the relationships among concepts; and classifying concepts, examples, or phenomena into correct categories.

Examples of the teaching moves that can enhance synthesis and creation are as follows: promoting careful observation, analysis, description, and definition; explaining the process and methods of scientific inquiry and scientific research; explaining and providing examples of how to identify a research problem; speculate about causes; formulating testable hypotheses; identifying and interpreting results and consequences; modeling inquiry and discovery processes; encourage independent thinking; showing students examples of creativity to solve problems; encouraging students to take novel approaches; explaining economic phenomena in a simple way by using metaphors and analogies; providing students with examples of reframing a problem; explaining and encouraging brainstorming; designing a research study to resolve a conflicting finding; writing the limitations section of a research study; and finally, practicing reframing a problem.

Examples of the teaching moves that can enhance evaluation are as follows: creating conflict by posing paradoxes, dilemmas, or other situations to challenge students' concepts, beliefs, ideas, and attitudes; explaining how to recognize and generate proof, logic, argument, and criteria for judgments; explaining and showing students the consequences of choices, actions, behaviors, making assumptions, and imposing structures to models; challenging definitions; identifying factors that influence choice and interpretations; detecting mistakes, false analogies, relevant versus irrelevant issues, contradictions, and faulty predictions; and finally, critiquing a research study.

Next section provides a graphic that links major teaching methods with cognitive learning outcomes. 


\section{Matching Major Teaching Methods with Learning Outcomes}

In this section, the teaching methods explained briefly in section 5.2 are to be visually linked to their corresponding cognitive learning outcomes. The cognitive learning outcomes are the ones explained in section 4, the ones initially put forth by Bloom (1956), which include: Knowledge, Comprehension, Application, Analysis, Synthesis, and Evaluation. Figure 2 brings these cognitive learning outcomes and their corresponding major teaching methods together. This figure answers the question of "which methods should be used for which outcomes?" It also shows which cognitive learning outcomes are more relevant to economics undergraduate studies, and which ones to economics graduate studies. Although the cognitive learning outcome of 'analysis' could be thought of as being on the border of the two, it is here considered to be one of the desired outcomes for the graduate schools, while it could also be part of the learning outcomes for senior undergraduate economics students.

\section{Relevance to the level of study in economics}

\section{Different levels in the cognitive domain}

\author{
Associated abilities \\ and activities with \\ each cognitive level
}

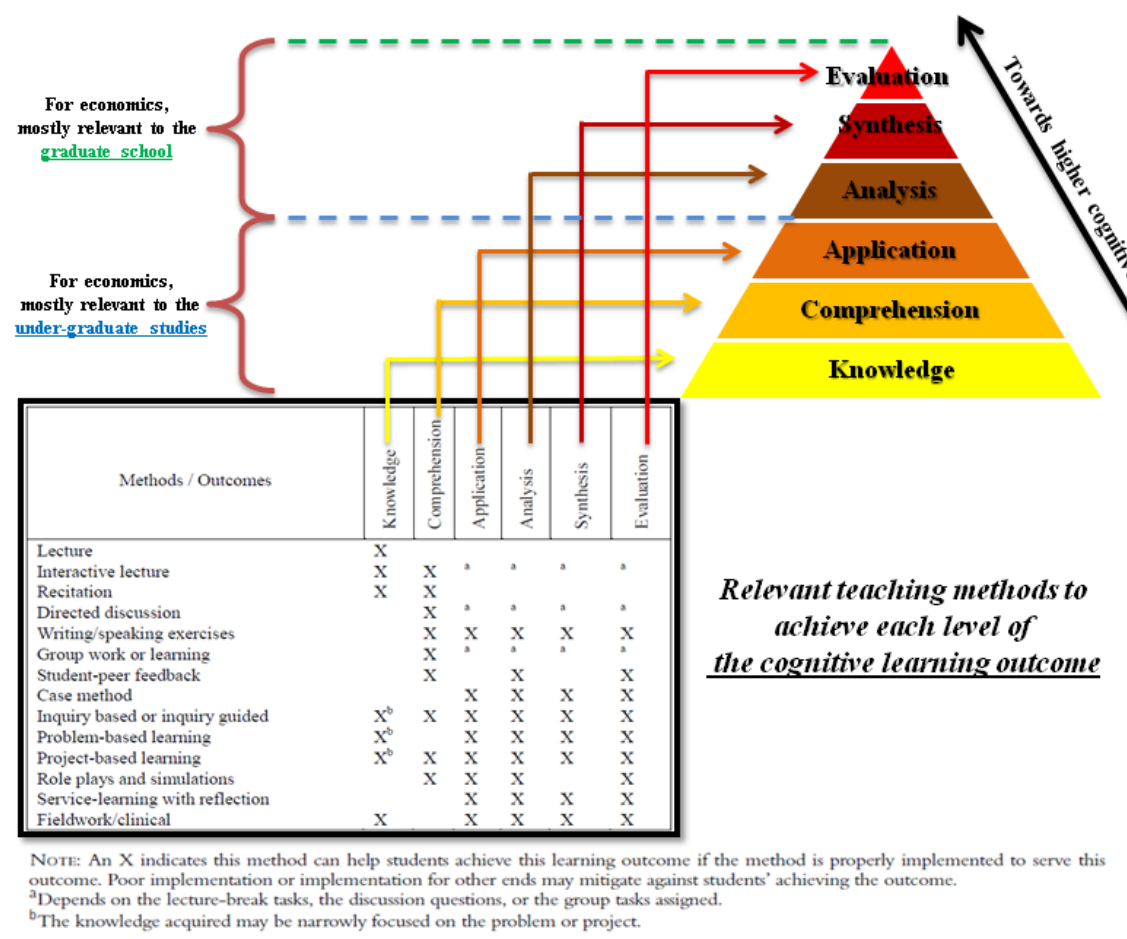

Figure 2. A graphic exhibiting the relationship among the levels of the cognitive domain, abilities, outcomes, and the associated teaching methods (The table used has been adopted from Nilson (2010))

As Figure 2 graphically illustrates, all the dimensions of a course must be built on the foundation of the anticipated learning outcomes of the course, which are instructors' ends throughout the term. The teaching methods listed in the above table are in fact the means to the pre-specified ends. As noted earlier, these ends should guide the choice of the means in an optimal way.

The triangle in Figure 2, which is known as Bloom's taxonomy, represents a set of hierarchical cognitive levels in terms of complexity levels. The column on the right lists the associated performance verbs, abilities, and activities for each of the cognitive levels. If the cognitive learning outcomes specified for a course go beyond the foundation (i.e. knowledge), then instructors need to be familiar with multiple means that can assist them in making their student achieve those higher-order learning outcomes. In the past, lecture was the only main teaching method employed in many areas, but thanks to recent research on the effectiveness of other teaching methods, we now know a wide range of teaching methods that work well for different purposes. The table presented in figure 2 introduces a toolbox full of teaching methods, from which instructors can select the most appropriate teaching method, or the most appropriate combination of teaching methods, that is the most suitable 
for their specified course cognitive learning outcomes. Therefore, one major task that any instructor must undertake is to select the optimal teaching method or the optimal combination of teaching methods that will help them and their students, in the best way possible, achieve the anticipated cognitive learning outcomes of the course.

\section{Conclusion and Summary}

The choice of teaching tools is a key determinant of the extent to which the anticipated learning outcomes of a course will be realized. As such, selecting optimal teaching tools can be a greatly effective task to enhance learning in the classroom, and it is ironic that economists, who are interested in finding optimality, sometimes do not behave optimally when it comes to their approach to teaching economics. This paper first explains cognitive learning outcomes, and reviews both traditional and modern teaching tools in the context of economics. Afterwards, the appropriate teaching tools that match correspondingly with each specific cognitive learning outcome are proposed for the setting of teaching economics using Bloom's (1956) taxonomy of cognitive domains to describe different cognitive learning levels. Then, a diverse set of teaching tools suitable to teach economics are corresponded to different cognitive learning outcomes. The aim of the paper is to introduce various teaching tools - including course formats, major teaching methods, and teaching moves - corresponding to different levels of cognitive domain in the context of teaching economics. In the end, it was argued that economics instructors should select teaching tools as well as contents, readings, in-class activities, assignments, and assessment formats after formulating the learning outcomes of the course, so that the teaching tools chosen can ease students' learning and help them attain the expected learning outcomes more readily.

The optimum teaching tools are the ones that maximize the achieved level of the pre-specified learning outcomes of the course. Although finding such an optimal point could potentially be highly costly and time-consuming, if not practically unfeasible, for economics instructors, there are still compelling pieces of evidence in the literature of education as well as some common understanding and consensuses among economics educators working on different areas in economics, following which can ensure economics instructors that they are indeed converging to the mentioned optimal point, i.e. the utilization of optimal teaching tools that maximizes the level of learning outcomes.

After having a brief literature review, it is seen that although there are studies that have tried to address the idea of matching teaching tools with students' learning styles or with other factors, less, if not no, attention has been paid to matching teaching tools to the cognitive learning outcomes in the context of teaching economics, and this is the existing gap in the literature that the present paper attempted to fill in.

Learning outcomes are of five types: psychomotor, affective, social, ethical, and cognitive. Among these, teaching economics has more to do with the last two ones. That is, normative economics has mainly to do with ethical learning outcomes, and positive economics has mostly to do with cognitive outcomes. Among these two, this paper focuses on the latter since teaching positive economics is the main component of economics curriculum in universities nowadays.

The cognitive learning outcomes include: Knowledge, Comprehension, Application, Analysis, Synthesis, and Evaluation. The first two cognitive levels indeed furnish foundations, and as a result, should not be considered as the endpoint of education. After building up such a concrete foundation, instructors can foster critical-thinking and problem-solving skills. Then, instructors can expect students to get engaged in challenging underlying assumptions of models, structure of methods, and the like. As such, in economics education, the lower levels of the cognitive domain have more to do with the anticipated cognitive learning outcomes of undergraduate economics studies, whilst the higher levels of it have more to do with the anticipated cognitive learning outcomes of graduate economics studies, during which students are usually expected to be able to contribute to a cause, and create something new.

Teaching tools can be broadly classified under three categories: course formats, major teaching methods, and teaching moves. A course format defines the course meetings, the setting, and the expected activities for the class period. Teaching methods require considerable time to be completed, e.g. the whole semester duration, or at least multiple weeks of it. Teaching moves should be viewed as mini methods compared to major teaching methods, which usually require comparably much less time and commitment. One advantage of teaching moves is that they are a highly flexible set of teaching tools, since they can be changed even during the course according to the feedback the instructor receives from the students, as opposed to course formats that are hardest teaching tool to be changed once the course has started. An additional advantage of teaching moves is the quick feedback that the instructor can get on his students' possible misapprehension and mistaken learning. In this sense, many of teaching moves can serve as both assessment tools and teaching tools. Afterwards, different examples of 
teaching moves that can enhance different levels of cognitive domains were provided. After that, a graphic was presented that links major teaching methods with cognitive learning outcomes. This figure answers the question of "which methods should be used for which outcomes?" It also shows which cognitive learning outcomes are more relevant to economics undergraduate studies, and which ones to economics graduate studies.

The figure introduces a toolbox full of teaching methods, from which instructors can select the most appropriate teaching method, or the most appropriate combination of teaching methods, that is the most suitable ones for their specified course cognitive learning outcomes. Since the ultimate goal of teaching is to help students achieve learning outcomes of the course, it makes the most sense to design the course delivery method according to the course learning objectives and outcomes from the first place. Therefore, one major task that any instructor must undertake is to select the optimal teaching method or the optimal combination of teaching methods that will help them and their students, in the best way possible, achieve the anticipated cognitive learning outcomes of the course.

\section{References}

Bartlett, R. L., \& King, P. G. (1990). Teaching economics as a laboratory science. The Journal of Economic Education, 21(2), 181-193.

Becker, W. E., \& Watts, M. (1995). Teaching tools: Teaching methods in undergraduate economics. Economic Inquiry, 33(4), 692-700.

Bloom, B. S. (1956). Taxonomy of educational objectives: The classification of educational goals.

Bloom, B. S. (1956). Taxonomy of educational objectives: The classification of educational goals: Cognitive Domain. Longman.

Bloom, B. S. (1956). Taxonomy of educational objectives: The classification of education goals by a committee of college and university examiners. David McKay.

Cross, K. P. (1988). In Search of Zippers. AAHE Bulletin, 40(10), 3-7.

Cross, K. P., \& Angelo, T. A. (1988). Classroom Assessment Techniques. A Handbook for Faculty.

Crowe, R. (2000). Know Your Student's Learning Style: The Missing Link in the Lecture vs. Active Learning Issue.

Felder, R. M., \& Silverman, L.K. (1988). Learning and Teaching Styles in Engineering Education. Engineering Education, 78 (7), 674-681.

Fish, R. S., \& McKeen, R. L. (1985). Accommodating different learning needs in economics education at the community college. Community/Junior College Quarterly of Research and Practice, 9(4), 325-332. http://dx.doi.org/10.1080/0361697850090403

Frank, R. H. (2007). The Dismal Science, Dismally Taught. Economic View, Sunday Business, New York Times, August 12: BU 4.

Goodson, L. (2005, March). Content, presentation and learning activities. Paper presented at the 26th annual meeting of the Sharing Conference of the Southern Regional Faculty and Instructional Development Consortium, Lake Junaluska, NC.

Holt, C. A. (1999). Teaching economics with classroom experiments: A symposium. Southern Economic Journal, 603-610.

Holt, C. A., \& Laury, S. K. (1997). Classroom games: Voluntary provision of a public good. The Journal of Economic Perspectives, 11(4), 209-215.

Hoyt, D. P., \& Perera, S. (2000). Teaching approach, instructional objectives and learning. IDEA Research Report, 1 .

Moosavian, S. A. Z. N. (2016a). A Comprehensive Visual "Wheel of Duality" in Consumer Theory. International Advances in Economic Research, 1-2. http:/dx.doi.org/ 10.1007/s11294-016-9586-8

Moosavian, S. A. Z. N. (2016b). Teaching Economics and Providing Visual "Big Pictures". arXiv preprint arXiv:1601.01771.

Moosavian, S. A. Z. N. (2016c). Teaching Economics and Providing Visual "Big Pictures". Journal of Economics and Political Economy, 3(1), 119-133. http://dx.doi.org/10.1453/jepe.v3i1.631

Moosavian, S. A. Z. N. (2016d). The Visual 'Big Picture' of Intermediate Macroeconomics. International 
Journal of Economics and Finance, 8(9), 234-248. http://dx.doi.org/10.5539/ijef.v8n9p234

Moosavian, S. A. Z. N. (2016e). The Visual Decoding of the "Wheel of Duality" in Consumer Theory in Modern Microeconomics: An Instructional Tool Usable in Advanced Microeconomics to Turn "Pain" into "Joy". Applied Economics and Finance, 3(3), 288-304. http://dx.doi.org/10.11114/aef.v3i3.1718

Moosavian, S. A. Z. N. (2017a). Using the Interactive, Graphic Syllabus in the Teaching of Economics. American Journal of Business Education, In Press.

Moosavian, S. A. Z. N. (2017b). Classicals versus Keynesians: A Comprehensive Table to Teach 50 Distinctions between Two Major Schools of Economic Thought. Manuscript in preparation.

Moryl, R. L. (2015). Pod Learning: Student Groups Create Podcasts to Achieve Economics Learning Goals. Available at SSRN 2638457.

Naumenko, A., \& Zeytoon, N. M. S. A. (2016). Clarifying Theoretical Intricacies through the Use of Conceptual Visualization: Case of Production Theory in Advanced Microeconomics. Applied Economics and Finance, $3(3), 103-122$.

Nilson, L. B. (2009). The Graphic Syllabus and the outcomes map: Communicating your course (Vol. 137). John Wiley \& Sons.

Nilson, L. B. (2010). Teaching at its best: A research-based resource for college instructors. John Wiley \& Sons.

Reich, R. B. (2000). One Education Does Not Fit All. New York Times, July 11: A25.

Richards, S. L. (2003). The Interactive Syllabus: A resource-based, constructivist approach to learning. The Technology Source.

Terregrossa, R. A., \& Englander, V. (2001). Teaching college economics: Efficiency issues. Journal of Private Enterprise, 17(Fall 2001), 52-60.

Terregrossa, R. A., Englander, F., \& Wang, Z. (2009). Why learning styles matter for student achievement in college economics. Journal for Economic Educators, 9(1), 16-31.

Tulbure, C. (2012). Learning styles, teaching strategies and academic achievement in higher education: A cross-sectional investigation. Procedia-Social and Behavioral Sciences, 33, 398-402.

Watts, M., \& Christopher, C. (2012). Using art (paintings, drawings, and engravings) to teach economics. The Journal of Economic Education, 43(4), 408-422.

Zeytoon, N. Moosavian S.A. (2016, June), Employing Technology in Providing an Interactive, Visual "Big Picture" for Macroeconomics: A Major Step Forward towards the Web-Based, Interactive, and Graphic Syllabus, Paper presented at the Sixth Annual American Economic Association (AEA) Conference on Teaching and Research in Economic Education (CTREE), Atlanta, GA, USA.

Zhang, H. (2016). Accommodating Different Learning Styles in the Teaching of Economics: with Emphasis on Fleming and Mills's Sensory-based Learning Style Typology. Applied Economics and Finance, 4(1), 72-83.

\section{Notes}

Note 1. Another way of classifying learning outcomes is to do so in terms of designing the learning process, in which they are classified in three types: foundational outcomes, mediating outcomes, and ultimate outcomes.

Note 2. It is beyond the scope of the present paper to further explain all the types of learning outcomes. However, for further information and elaboration on these, you can see Nilson (2010).

Note 3. Exhibit 2 presented in section 6 will provide further information on Bloom's taxonomy in a visual manner.

\section{Appendix}

A short explanation of each teaching method (adopted from Nilson (2010))

- Lecture: Instructor presenting material and answering student questions that arise.

- Interactive lecture: Lecture with two- to fifteen-minute breaks for student activities (such as answering a multiple-choice objective item, solving a problem, comparing and filling in lecture notes, debriefing a mini case, doing a think pair-share exercise, or a small-group discussion) every twelve to twenty minutes. 
- Recitation: Students answering knowledge and comprehension questions.

- Directed discussion: Class discussion that follows a more or less orderly set of questions that the instructor has crafted to lead students to certain realizations or conclusions or to help them meet a specific learning outcome.

- Writing and speaking exercises: Any of many informal assignments and activities, usually in-class and ungraded, to help students learn material, clarify their thinking, or make progress on a formal assignment.

- Classroom assessment techniques: Informal assignments and activities, usually in-class and ungraded, to inform the instructor how well students are mastering new material just presented or read; often overlap with writing and speaking exercises.

- Group work/learning: Students doing a learning activity or creating a product in small groups of two to six in or out of class; must be carefully managed by the instructor.

- Student-peer feedback: Students giving one another feedback on a written or an orally presented product, usually a written draft or practice speech.

- Cookbook science labs: Pairs or triads of students conducting a traditional, often predictable experiment following prescribed, cookbook-like procedures.

- Just-in-time teaching: Instructor adjusts class activities and lectures to respond to the misconceptions revealed by students' electronic responses to conceptual questions; an extension of electronic daily quizzes to motivate students to do the readings.

- Case method: Students applying course knowledge to devise one or more solutions or resolutions to problems or dilemmas presented in a realistic story or situation; an individual, small-group, or whole class activity.

- Inquiry-based or inquiry-guided learning: Students learning or applying material in order to meet a challenge, such as to answer a question, conduct an experiment, or interpret data.

- Problem-based learning: Student groups conducting outside research on student-identified learning issues (unknowns) to devise one or more solutions or resolutions to fuzzy problems or dilemmas presented in a realistic story or situation.

- Project-based learning: Students (as individuals or in groups) applying course knowledge to produce something, such as a report (written or oral), process or product design, research or program proposal, or computer code; often paired with cooperative learning.

- Role plays: Students acting out instructor-assigned roles, improvising the script, in a realistic and problematic social or interpersonal situation.

- Simulations: Students playing out, either face to- face or on computer, a hypothetical social situation that abstracts key elements from reality.

- Service-learning with reflection: Students learning from the experience of performing community service and systematically reflecting on it.

- Fieldwork and clinicals: Students learning how to conduct research and make sound professional judgments in real-world situations.

\section{Copyrights}

Copyright for this article is retained by the author(s), with first publication rights granted to the journal.

This is an open-access article distributed under the terms and conditions of the Creative Commons Attribution license (http://creativecommons.org/licenses/by/4.0/). 